www.jmscr.igmpublication.org

Index Copernicus Value: 79.54

ISSN (e)-2347-176x ISSN (p) 2455-0450

crossrefDOI: https://dx.doi.org/10.18535/jmscr/v7i2.39

\title{
Radiographic Evaluation of Adenoidal Size in Children Having Otitis Media with Effusion
}

\author{
Authors \\ Sunaina Binth Hamza ${ }^{1}$, Ranjith $\mathrm{V}^{\mathbf{2}^{*}}$ \\ ${ }^{1,2}$ Department of ENT, Government Medical College, Thrissur \\ *Corresponding Author \\ Ranjith V T \\ Deepakam, Green Gardens, Chittilappilly P.O, Thrissur, Kerala, India \\ Mob 9895655562, Email: vtranjith@gmail.com
}

\begin{abstract}
Otitis media with effusion (OME) due to chronic adenoiditis is one of the most common chronic otological problems dealt by otorhinolaryngologists. It is defined as the chronic accumulation of mucus within the middle ear and sometimes the mastoid air cell system. The role of adenoids in the pathogenesis of OME is much debated. Several mechanisms have been described in literature for the pathogenesis of OME, the most accepted being displacement of eustachian tube orifice. The main objective of the study is to study the association between size of adenoids and occurrence of otitis media with effusion and to evaluate the grades of adenoid hypertrophy by lateral neck radiograph. This study gives support to the concept that the Adenoidal-nasopharyngeal ratio (ANR) is a conventional and convenient radiological parameter for determining whether adenoid hypertrophy is clinically significant or not, rather than the size of adenoid or the size of the nasopharynx alone

Keywords: Adenoidal -Nasopharyngeal ratio. X- ray Nasopharynx Lateral view. Eustachian Tube dysfunction.
\end{abstract}

\section{Introduction}

Adenoids are a mass of lymphoid tissue with definite function, namely the production of antibodies (IgA locally and $\operatorname{IgG} \& \operatorname{IgM}$ systemically). The size of the adenoids varies from patient to patient and also in the same individual as he/she grows. In general the normal adenoids attain their maximum size between the ages of 3 and 7 years and then regress ${ }^{1}$. What may be important in considering the harmful effects of the adenoids is the size in relation to that of the nasopharyn $x^{2}$. Adenoids cause eustachian tubal obstruction at its pharyngeal opening. A doubleblind placebo controlled study showed good reliability of digital $\mathrm{x}$-ray nasopharynx in assessing adenoid hypertrophy as it is noninvasive and well tolerated by children ${ }^{3}$

A case controlled study concluded that ratio measured on simple lateral skull radiography, correlated well with the clinical assessment and for all practical purposes value of a ratio greater than 0.73 may be considered indicative of pathological enlargement of the adenoids ${ }^{4}$. 


\section{Methods}

This study was conducted in the department of otorhinolaryngology, government medical college Thrissur, Kerala for a period of one year from October 2016 to September 2017.It was an observational cross sectional study and 100 patients were enrolled. The digital X-ray nasopharynx lateral view of all the patients were analysed to calculate the ANR and corresponding $\mathrm{X}$-ray grades were noted. The adenoidal measurement represents the distance from the point of maximal convexity of the adenoid shadow (A1-Fig.1\&2) anteroinferiorly to the anterior margin of the basiocciput (A-Fig.2). The nasopharyngeal measurement represents the distance between the posterior border of the hard palate and spheno basiocciput synchondrosis (b1b2 Fig. 2$)^{3}$

ANR will be graded as follows

- Grade 0 (0.0 - 0.25) no adenoid enlargement

- Grade I (0.26 - 0.50) minimal enlargement

- Grade II (0.51 -0.75) moderate enlargement

- Grade III (0.76 - 1.00) gross enlargement

Student $\mathrm{t}$ test was done to compare mean ANR with the presence of $\mathrm{OME}$ and statistically significant difference with a $\mathrm{p}$ value $0.024(<0.05)$ was obtained.

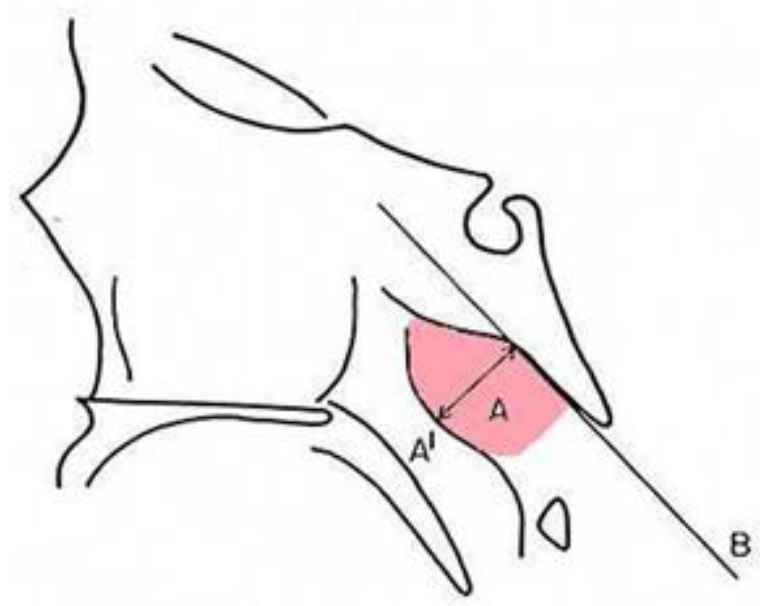

Fig.1

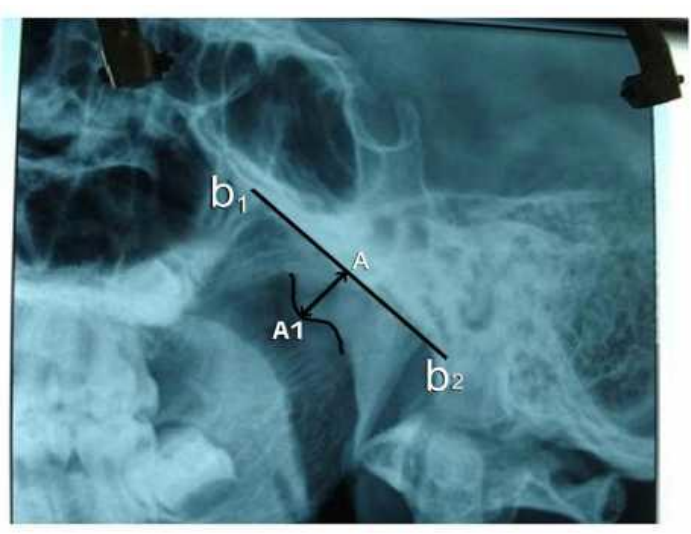

Fig.2

Adenoidal measurements. " $A$ " represents distance from A1, point of maximal convexity, along inferior margin of adenoid shadow to line b1 b2, drawn along straight part of anterior margin of basi-occiput. "A" is measured along line perpendicular from point $\mathrm{A} 1$ to its intersection with b1- b2.

\section{Results}

Majority of the children were in the age group 45years and 6-7 years in this study.

Most of the cases presented with snoring and mouth breathing $(n=75)$, nasal obstruction $(n=68)$, recurrent respiratory infections $(n=68)$ and hard of hearing $(n=62)$.

Table 1 Distribution of Cases in Various X-ray Grades

\begin{tabular}{|l|c|c|}
\hline ANR & X-ray Grade & No. Of cases \\
\hline $0-0.25$ & 0(no enlargement) & 0 \\
\hline $0.26-0.50$ & 1(minimal enlargement) & 1 \\
\hline $0.51-0.75$ & 2(moderate enlargement) & 63 \\
\hline $0.76-1.00$ & 3(gross enlargement) & 36 \\
\hline
\end{tabular}

Table 2 Mean Adenoidal-Nasopharyngeal Ratio

\begin{tabular}{|l|c|c|}
\hline AGE & NO. OF CASES & MEAN \\
\hline$>3-5$ & 31 & 0.6784 \\
\hline$>5-7$ & 28 & 0.7364 \\
\hline$>7-9$ & 17 & 0.7312 \\
\hline$>9-11$ & 16 & 0.6831 \\
\hline$>11-12$ & 8 & 0.7338 \\
\hline
\end{tabular}

Table 3 ANR VS OME

\begin{tabular}{|l|c|c|}
\hline OME & NO. OF CASES & MEAN(+/-SD) \\
\hline Present & 62 & $0.7223(+/-0.105)$ \\
\hline Absent & 38 & $0.6768(+/-0.081)$ \\
\hline
\end{tabular}


Table 4.OME VS X-ray Grades

\begin{tabular}{|l|c|c|c|}
\hline $\begin{array}{l}\text { X-ray } \\
\text { Grades }\end{array}$ & $\begin{array}{l}\text { OME (Either } \\
\text { or both ears) }\end{array}$ & No OME & $\begin{array}{c}\text { Total } \\
\text { Cases }\end{array}$ \\
\hline Grade 0 & 0 & 0 & 0 \\
\hline Grade 1 & $1(100 \%)$ & 0 & 1 \\
\hline Grade 2 & $32(50.8 \%)$ & $31(49.2 \%)$ & 63 \\
\hline Grade 3 & $29(80.6 \%)$ & $7(19.6 \%)$ & 36 \\
\hline Total & $\mathbf{6 2}$ & $\mathbf{3 8}$ & $\mathbf{1 0 0}$ \\
\hline
\end{tabular}

Mean ANR in the group with otitis media is 0.72 and by performing student $t$ test it was statistically proved to be of significant difference in the two groups

\section{Discussion}

This study shows close association between size of adenoids and occurrence of OME, as maximum number of cases corresponds to higher grades of adenoid hypertrophy (X-ray grade 2 and 3) Mean ANR for which OME present is 0.722 , which corresponds to X-ray grade 2 and shows statistically significant association of OME to adenoid size.

In this study the ANR is maximum at an average of 0.7364 in age group of 5-7 years and 0.7312 in 7-9 years, in whom the signs and symptoms of adenoid hypertrophy are more common. ANR gradually decreases to 0.683 in children of 9- 11 years of age which correlates with the study by M.Fujioka, W. Young and R. Girdany (1979) ${ }^{3}$.

\section{Conclusion}

There is significant association between the size of adenoids and occurrence of Otitis Media with Effusion. The proportion of OME increases with the severity of nasopharyngeal obstruction by adenoid hypertrophy.

Mean adenoid size of 0.72 (X-ray grade 2) according to ANR was mainly seen among patients having unilateral or bilateral OME. So an ANR of 0.72 should be considered as significant pathological enlargement and these children should be routinely sent for tympanometry. Although both X-ray and endoscopy are equally good in assessing the size of adenoids, the digital $\mathrm{X}$-ray Nasopharynx lateral view provides a more convenient method for determining whether the adenoid hyperplasia is clinically significant or not.

\section{References}

1. Sadler TW, Langman's Medical embryology, Baltimore, Maryland, USA, Willams and Wilkins, 1995; PP: 347-354.

2. Hibbert J, Whitehouse GH. The assessment of adenoidal size by radiological means. Clin otolaryngol,1978; 3: 43-47.

3. Fujioka M., Young L.W.,Girdany B.R. Radiographic evaluation of adenoidal size in children: adenoidal- nasopharyngeal ratio, American journal of Roentgenology 1979; 133: 401-404.

4. Kurien M., Lepcha A., Mathew John, Ali Arif, Jayasheelan L. X-rays in the evaluation of adenoid hypertrophy: it's role in the endoscopic era, Indian journal of Otolaryngology and head and neck surgery March 2005; 57: 45-47. 